\title{
Pepsin secretion in man after Histalog stimulation
}

MICHAEL D. TURNER, PAULA J. MAYER, LEON L. MILLER, AND HARRY L. SEGAL

From the Isaac Gordon Laboratory for Gastrointestinal Research, University of Rochester School of Medicine and Dentistry, 260 Crittenden Boulevard, Rochester, New York

SUMMARY Human gastric juice shows three separable pepsin fractions on chromatography on DEAE-cellulose. The response of these fractions to stimulation with $\beta$-aminoethylpyrazole hydrochloride (Histalog) was studied. After a single intramuscular injection of Histalog (1.7 $\mathrm{mg} / \mathrm{kg}$ body weight) there was an increase in the output of all three chromatographically distinguishable pepsin fractions. Little change was observed in the relative proportions of these three fractions and there was no evidence of selective stimulation of any individual fraction.

Many previous studies of the secretion of pepsin in man have appeared. These, for the most part, have regarded pepsin as a single substance and have taken no account of the fact that human 'pepsin' is composed of a number of different proteinases. It now appears that human gastric mucosa contains at least seven distinguishable proteinase proenzymes (Turner, Mangla, Samloff, Miller, and Segal, 1970) which are the precursors of a number of pepsins which are found in the gastric juice. Although, as yet, it is not clear how many individual enzymes result from the activation of these zymogens, and no method has yet been developed for the quantitative measurement of each individually, Seijffers, Segal, and Miller (1964) were able to separate human pepsin into three distinct fractions which could be measured quantitatively by chromatography on DEAE-cellulose. These fractions were termed 'pepsin I', 'pepsin II', and 'pepsin III'. It is the purpose of this communication to report the results of the application of this chromatographic technique to the study of gastric juice specimens obtained from three normal subjects after stimulation with Histalog ( $\beta$-aminoethylpyrazole hydrochloride).

'Supported by grants CA-09546 from the National Cancer Institute and 5-TO1-AM 5177 from the National Institute of Arthritis and Metabolic Diseases, United States Public Health Service.

Received for publication 1 April 1970.

\section{Materials and Methods}

DEAE-cellulose (lot no. 1410) was obtained from the Brown Chemical Company (Berlin, New Hampshire, USA), bovine haemoglobin type II (lot no. 107B-1340) was obtained from the Sigma Chemical Company (St Louis, Missouri, USA), and Histalog was a gift of the Eli Lilly Company. $0 \cdot 1 \mathrm{M}$ acetate buffer ( $p \mathrm{H} 5 \cdot 3$ ) was made from $0 \cdot 1 \mathrm{M}$ sodium acetate and $0 \cdot 1 \mathrm{M}$ acetic acid. Appropriate amounts of sodium chloride, as described below, were added for gradientelution chromatography (Seijffers et al, 1964).

Three healthy subjects in their third decade, two male and one female, who gave no history of dyspepsia or other gastrointestinal disorders, took part in this investigation. After an overnight fast, the subject swallowed a fine radioopaque plastic nasogastric tube. The position of the tube was checked by radiography and its tip adjusted to lie approximately three-quarters of the way down the greater curvature of the stomach. The subject thereafter lay on the left side throughout the test. Saliva was expectorated as it was produced and the gastric juice removed by continuous hand aspiration and placed in a beaker standing in crushed ice. After the resting juice had been removed, two specimens of the basal secretion, each produced over a period of 15 minutes, were obtained; these were collected separately. Histalog was then injected intra- 
muscularly in a dose of $1.7 \mathrm{mg} / \mathrm{kg}$ body weight and specimens of gastric juice were collected corresponding to each 15 -minute period. The experiment was stopped after four 15-minute specimens, taken after the injection of Histalog, had been obtained from subjects 1 and 2 and after five specimens had been taken from subject 3 .

The volume of each specimen of gastric juice was measured and an aliquot taken for $p H$ measurement and for determination of acid by titration to $p \mathrm{H} 7 \cdot 4$. A second aliquot was mixed with three times its volume of ice-cold $0.1 \mathrm{M}$ acetate buffer $(p \mathrm{H} 5 \cdot 3)$. At the end of the collection, the $p \mathrm{H}$ of the gastric juice-buffer mixtures was adjusted to $p \mathrm{H} 5 \cdot 30$ by the addition of $2 \mathrm{M}$ sodium acetate. The mixtures were then dialysed overnight against a large volume of $0 \cdot 1 \mathrm{M}$ acetate buffer $(p H 5 \cdot 3)$ and centrifuged at $4^{\circ} \mathrm{C}$ at 13,000 $\mathrm{rpm}$ in an angle head $30 \mathrm{~cm}$ in diameter for one hour. The precipitate was discarded, the volume of the supernatant determined, and measured aliquots were frozen in a number of separate tubes and stored at $-20^{\circ} \mathrm{C}$. One tube was thawed and used for each analysis in order to avoid repeated thawing and freezing.

\section{MEASUREMENT OF PEPTIC ACTIVITY}

Aliquots of the second specimen of basal secretion and all specimens taken after Histalog were diluted with $0 \cdot 1 \mathrm{M}$ acetate buffer $(p \mathrm{H} \mathrm{5.30)}$ and assayed using a modification of the procedure of Anson and Mirsky (1932) with Folin-Ciocalteu reagent as described by Seijffers, Segal, and Miller (1963). The specimens were diluted sufficiently to give results in the near-linear range of the method. The gastric juice buffer mixtures usually required dilution $1: 100$, but in a few instances dilution 1:200 was necessary. One unit of proteolytic activity was arbitrarily defined as that amount of enzyme in $1 \mathrm{ml}$ of solution which would release an average of $1 \mu \mathrm{mol}(281 \mu \mathrm{g})$ of 'tyrosine-like substance' per minute from $5 \mathrm{ml}$ of $2 \%$ acid haemoglobin substrate during incubation at $37^{\circ} \mathrm{C}$ for one hour.

\section{COLUMN CHROMATOGRAPHY OF GASTRIC JUICE}

The second specimen of basal secretion and all post-Histalog specimens of gastric juice were analysed by chromatography on a column of DEAE-cellulose $2 \times 19.5 \mathrm{~cm}$ prepared as described by Seijffers et al (1964). An amount of each specimen containing 73.5 units of peptic activity was loaded on to each column. After loading, the column was washed with $100 \mathrm{ml}$ of $0.1 \mathrm{M}$ acetate buffer $(p \mathrm{H} \mathrm{5.3)}$ containing $0 \cdot 1 \mathrm{M}$ sodium chloride and then with $200 \mathrm{ml}$ of $0 \cdot 1 \mathrm{M}$ acetate buffer $(p \mathrm{H} 5 \cdot 3)$ containing $0.2 \mathrm{M}$ sodium chloride. The column was then eluted with buffers containing an increasing concentration of sodium chloride. The chloride gradient was generated in a Varigrad composed of nine cylinders each of which contained 250 $\mathrm{ml}$ of buffer. The concentrations of sodium chloride in the nine cylinders in sequence from first to last were: $0.240,0.240,0.245$, $0.245,0.255,0.260,0.270,0.300$, and 0.350 . The temperature was maintained throughout at $18^{\circ} \pm 0 \cdot 1^{\circ} \mathrm{C}$ by circulating water from a thermostatically controlled bath through the column jacket. The column was eluted at a flow rate of approximately $50 \mathrm{ml}$ per hour and fractions of $15 \mathrm{ml}$ were collected and were analysed for proteolytic activity by the 'standard radioactive assay' of Turner, Tuxill, Miller, and Segal (1966). All such assays were controlled by the inclusion of a known standard pepsin solution so that the results could be expressed in terms of units of peptic activity.

\section{Results}

All the subjects showed an increase in hydrochloric acid output after Histalog administration (Table). The female subject (no. 2) showed only a small response to Histalog, secreting $6 \cdot 13$ m-equiv of acid in an hour following the injection. The two male subjects (nos. 1 and 3 ) secreted 13.48 and 23.7 m-equiv of acid respectively in the hour following stimulation. The maximum output occurred in the specimen collected between 15 and 30 minutes after the stimulant in subject 1 , between 45 and 60 minutes in subject 2 , and in the extra specimen collected between 60 and 75 minutes from subject 3 .

The rate of total pepsin output into the stomach increased in all three subjects after Histalog, the greatest increments in the three subjects being $270 \%, 565 \%$, and $382 \%$ respectively. These were observed in the collections made between 15 and 30 minutes in subjects 1 and 2 and in the specimen taken between 30 and 45 minutes in subject 3 (Fig. 1). In subject 1 the peak of pepsin output appeared to correspond to the peak of acid output, whereas in subjects 2 and 3 peak pepsin output preceded peak acid output.

The proportion of the three chromatographically distinguishable pepsin fractions varied only slightly from specimen to specimen in the three individuals studied (Fig. 2). In subject 1 , fraction I varied from 22 to $26.5 \%$ of the total pepsin and fraction II from 6.0 to $9.3 \%$, fraction III comprising the remainder. In subject 2 fraction I varied from 13.7 to $233 \%$, fraction II from 6 to $10 \cdot 7 \%$, and fraction III from 66.0 to $77.0 \%$. Subject 3 showed: fraction I, 22 to $26.5 \%$, fraction II, 6.0 to $9.3 \%$, and fraction III $66 \cdot 2$ to $70 \cdot 6 \%$. These fluctuations were obviously much less proportionately than the increment in total pepsin secretion observed in the different specimens after Histalog. Moreover variations 


\begin{tabular}{|c|c|c|c|c|c|c|}
\hline \multirow{3}{*}{ Subject } & \multicolumn{6}{|c|}{ Acid Secretion (m-equiv/15 min) } \\
\hline & \multirow[t]{2}{*}{ Basal } & \multicolumn{5}{|c|}{ After Histalog Administration } \\
\hline & & $0-15 \mathrm{~min}$ & $15-30 \mathrm{~min}$ & $30-45 \mathrm{~min}$ & $45-60 \mathrm{~min}$ & $60-75 \min$ \\
\hline $\begin{array}{l}1 \\
2 \\
3\end{array}$ & $\begin{array}{l}0.96 \\
0.065 \\
0.19\end{array}$ & $\begin{array}{l}0.73 \\
0.13 \\
0.94\end{array}$ & $\begin{array}{l}4 \cdot 87 \\
1 \cdot 4 \\
5 \cdot 58\end{array}$ & $\begin{array}{l}4 \cdot 76 \\
1 \cdot 7 \\
8 \cdot 63\end{array}$ & $\begin{array}{l}3 \cdot 12 \\
2 \cdot 9 \\
8 \cdot 51\end{array}$ & $\overline{\overline{8}} \overline{83}$ \\
\hline
\end{tabular}

Table Acid secretion before and after administration of Histalog
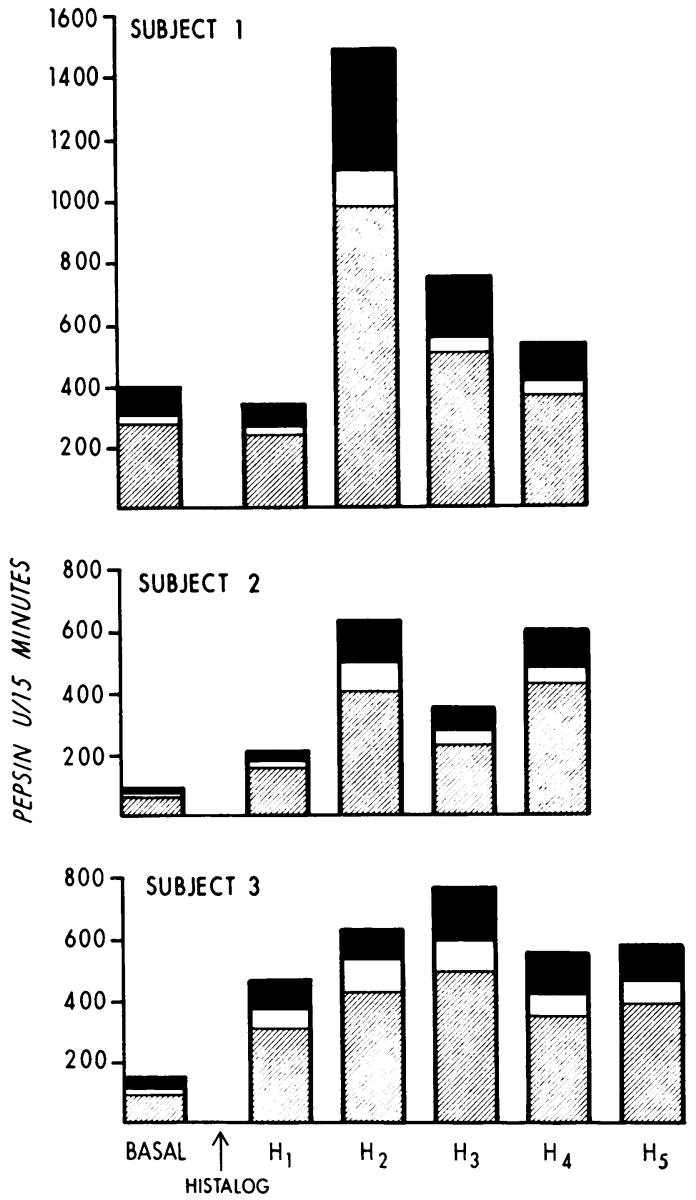

Fig. 1 Secretory response of pepsins to Histalog. Ordinate shows output in units per 15 minutes. $H_{1}, H_{2}$, etc. represent specimens of gastric juice collected in sequential 15-minute periods after Histalog. Note that an increase in the output of all three chromatographically distinguishable pepsin fractions occurs after Histalog. (Here and in Fig. 2 the black area indicates pepsin fraction I, the white area pepsin fraction II, and the shaded area pepsin fraction III.)

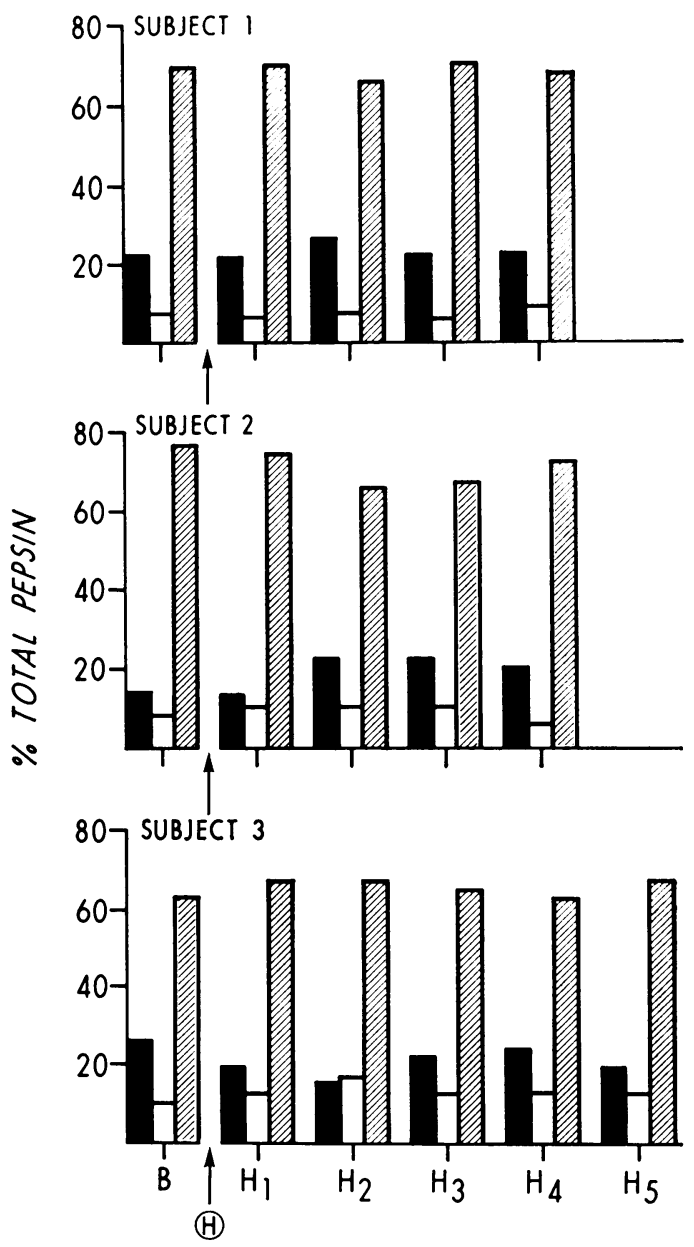

Fig. 2 Proportions of the three chromatographically distinguishable pepsin fractions in sequential 15. minute specimens of gastric juice after Histalog. Note that there is little change in the proportions of the three pepsin fractions in the different specimens. The point at which Histalog was given is shown by the arrow.

in the proportions of the three pepsin fractions in the different specimens appeared random and no systematic pattern of change was seen after Histalog stimulation.

\section{Discussion}

The chromatographic technique gave reasonably reproducible results (Seijffers et al, 1964) but temperature control was critical to obtain satisfactory separation of the three pepsin fractions. However, even with satisfactory chromatograms it was not possible to determine the proportions 
of the three fractions with great accuracy and much of the variation observed in the percentage composition of the individual specimens must therefore represent experimental error. The variations which were observed in the percentage composition of individual specimens after Hista$\log$ were of much less magnitude than the change in total pepsin output, and there can therefore be no doubt that an increase in the output of all the three chromatographically distinguishable pepsin fractions followed the intramuscular administration of a single dose of Histalog. The variations observed in the proportions of the three distinguishable pepsin fractions were small and there was no evidence for a selective stimulation of any of the three pepsin fractions.

Although studies on only three subjects are reported here, the chromatographic techniques employed in the analyses are so time-consuming that further studies did not appear warranted. The results obtained from the three subjects did, however, confirm the observations made in one other normal man which have previously been briefly reported (Segal, Seijffers, Miller, and Turner, 1966). More information on the pattern of pepsin response to stimulation with other gastric secretagogues must await the development of less tedious methods for the measurement of the individual pepsins. Some initial steps have already been made in that direction (Chiang, SanchezChiang, Wolf, and Tang, 1966; Turner, Tuxill, Miller, and Segal, 1967).

We are grateful to Eli Lilly and Company for the Histalog used in these experiments.

References

Anson, M. L., and Mirsky, A. E. (1932). The estimation of pepsin with hemoglobin. J. Gen. Physiol., 16, 59-63.

Chiang, L., Sanchez-Chiang, L., Wolf, S, and Tang, J. (1966). The separate determination of human pepsin and gastricsin. Proc. Soc. exp. Biol. (N.Y.), 122, 700-704

Segal, H. L., Seijffers, M. J., Miller, L. L., and Turner, M. D. (1966). Chromatographic separation of human pepsinogens and pepsins. Proc. IIIrd World Congress of Gastroenterology, $1,418-421$.

Seijffers, M. J., Segal, H. L., and Miller, L. L. (1963). Separation of pepsin I, pepsin IIA, pepsin IIB, and pepsinogen III from human gastric mucosa. Amer. J. Physiol., 205, 1099-1105.

Seijffers, M. J., Segal, H. L., and Miller, L. L. (1964). Chromatographic separation of pepsins from human gastric juice. Amer. J. Physiol., 207, 8-12.

Turner, M. D., Mangla, J. C., Samloff, I. M., Miller, L. L., and Segal, H. L. (1970). Studies on the heterogeneity of human gastric zymogens. Biochem. J., 116, 397-404.

Turner, M. D., Tuxill, J. L., Miller, L. L., and Segal, H. L. (1966). An ultramicro method for the measurement of pepsin. Analyt. Biochem., 16, 487-499.

Turner, M. D., Tuxill, J. L., Miller, L. L., and Segal, H. L. (1967). Measurement of pepsin I (gastricsin) in human gastric juice. Gastroenterology, 53, 905-911. 